\title{
ethic \\ THE CASE FOR DEMOCRATIC PATIENTS: EPISTEMIC DEMOCRACY GOES GREEN
}

\author{
ANDRÉS CRUZ ${ }^{1}$ \\ (Pontificia Universidad Católica de Chile / Chile)
}

\begin{abstract}
In mainstream democratic theory, non-agents are only considered indirectly: their interests matter if and only if a group of agents cares about them. In this paper, I argue that democratic patients, non-agents whose interests are affected by democratic decisions, have a place of their own in democratic theory. That is, they are entitled to the fair consideration of their interests in the democratic decision-making process. I defend the case for democratic patients by building upon the idea of epistemic democracy as proposed by David Estlund. If democratic procedures ought to be epistemically designed towards achieving right decisions, as Estlund argues, they should consider all relevant evidence fairly, like a jury does. Since democratic patients' interests are affected by democratic decisions, I argue that they do count as relevant evidence via the All-Affected Principle, which lies at the core of democracy. Then I present some candidates for being democratic patients, which include young children, severely cognitively disabled humans, non-existent future humans, sentient animals and even non-sentient life forms. Whether they turn out to be democratic patients depends on what theories one accepts about agency, interests, and the impact of the outcomes of democracy on interests. I illustrate that point by discussing future humans as possible candidates. Finally, I briefly explore the challenge of designing real-world institutions derived from my argument, outlining what objectives they should aim for and some of the problems they might face.
\end{abstract}

Keywords: Epistemic democracy; Non-agents; Environmental politics; All-Affected Principle

The almost unanimous position in democratic theory is that democracy is exclusively a matter of agents, not patients. Ben Saunders expresses the point nicely:

Rule in the interests of the people (or affected patients) is not democracy, but guardianship. ... Democracy is based on respecting people as agents, rather than merely as patients. This is why we should heed people's expressed wishes, rather than merely acting in their interests, and why outcomes should be sensitive to these inputs, rather than serving all interests equally $(2012,288)$.

Environmental political theory has accepted that position as true without further challenge. For instance, in a recent paper discussing the constraints and possibilities that democracy places on environmental action, Elisabeth Ellis says that "democratic arguments need not address the interests of beings outside the circle of enfranchised agents" $(2016,514)$. In this article I challenge this approach, arguing that some non-agents (those whose interests are affected by democratic decisions) should be of direct concern to democratic theory. Failing to consider their interests fairly, I argue, is a serious problem for democracy. 
While I believe that there are some deeper, moral reasons for considering the interests of some non-agents in the political sphere, the proposal developed here -structured around democratic theory- has a strategic appeal. It attempts to imbue the interests of those non-agents in a realm which is arguably less controversial than the one of deep moral beliefs; the realm of democratic, universal-aspiring procedures. This article, then, takes the lead of Robert Garner, who "seeks to justify including animals within the boundaries of the political community, not by employing contentious non-political ethical categories utilized in traditional animal ethics, but by reference to a political norm" $(2017,461)$. Here I adopt the same strategy, but potentially broaden its scope to not only include non-human animals, but also some other entities who are usually treated as non-agents.

In section $1 \mathrm{I}$ develop an argument for democratic patients -non-agents whose interests are affected by democratic decisions-, which is derived from an epistemic account of democracy (Estlund 2008) and the All-Affected Principle (Goodin 2007). In a nutshell, the argument goes as follows. Democracy is, at least partially, epistemically valuable. This is a premise of my argument, according to which the procedural quality of 'clearing the path' (e.g. avoiding biases and misinformation) in order to reach right decisions is desirable in a democracy. With the objective of clearing the path for right decisions to emerge, a democracy must consider all relevant evidence fairly, just like a jury does. I argue that the interests of democratic patients should count as relevant evidence in this context, because they are affected by democratic decisions. Via the All-Affected Principle, a core ideal of democracy, this gives them the right to have a voice in the process leading to those outcomes. Therefore, failing to fairly consider their interests would undermine democracy in epistemic terms.

Having done that, in section 2 I tackle the issue of how to determine whether an entity should be considered a democratic patient. I explore the three dimensions of democratic patients' defining characteristics: (a) not being capable of democratic agency, (b) having interests, and (c) having those interests affecting by democratic decisions. The subset of entities that one might refer to as democratic patients depends on the stands one takes regarding (a), (b), and (c). Be that as it may, in this section I do not choose between those competing theories, because the core argument for democratic patients only requires that there is a non-empty set of them, regardless of the specific group constitution. At the end of this section, I present future humans as an illustration of how to assess whether an entity is indeed a democratic patient, reviewing how they stand regarding (a), (b), and (c). 
Finally, in section 3 I present some closing remarks about the institutional challenge that arises from my argument: how can we fairly consider the interests of democratic patients in the real world? What institutional changes (if any) should we make, and how would they work? While not providing comprehensive answers to those questions, I do mention some objectives that any proposed institutional arrangement should meet, and some of the dangers related to the fulfillment of those objectives.

\section{The case for democratic patients}

Before going into the argument that -hopefully- renders the concept valuable, it is best to first outline the three defining attributes of democratic patients. They are individual entities ${ }^{2}$ who:

(a) are not capable of democratic agency,

(b) have interests,

and

(c) have their interests affected by democratic outcomes.

This definition by itself does not really tell us much about the composition of the group of democratic patients. Some potential candidates are young children, severely cognitively disabled humans, non-existent future humans, sentient animals, and non-sentient life forms. The exact definition of the group depends on what we believe to be the limits of agency, the limits of interests' possession, and the impact of the outcomes of democracy on interests, an idea that I will revisit in section 2. In this section I present the core of my argument for democratic patients, regardless of who they are.

\section{The epistemic value of democracy}

While agents are at the center of democracy, non-agents appear to be nowhere around. If democracy is understood narrowly, as a way of giving everyone with a voice an equal chance to influence political decisions (see Estlund 2008, 6), then this exclusive focus on democratic agents is justified, since non-agents are voiceless: they cannot directly influence the decisionmaking process (see Goodin 2003). Including them would simply be inconsistent with democracy's aims. 
However, that thin proceduralist conception of democracy is insufficient, or so I will claim from the perspective of epistemic democracy. As David Estlund (2008) argues, fairness of the procedure alone cannot explain why democracy has any importance at all. Flipping a coin is a procedure as fair as we can imagine -it gives each option an equal chance- and it seems wrong to suggest that political decisions should be taken by appealing to that criterion ${ }^{3}$. We think that we are better than a coin flip at deciding what is best for us: we (at least partially) value democracy in epistemic terms. In other words, democracy's outcomes are not irrelevant.

This does not mean that we should judge how well a democracy performs as a political system by looking at how just, good or even 'true' its outcomes are. Since these are contested assessments (for anyone who believes in pluralism about conceptions of the good, at least), that would not be a standard at all. A better way of evaluating the success of a democracy can be discovered by looking closely at Estlund's (2008) example of a jury. We know that juries err sometimes, but we still consider them legitimate. It is not the contingent correctness of juries what makes them attractive as public institutions, but the fact that their whole design aims at arriving at the right decisions. In other words, their procedures attempt to be as fair and epistemically-oriented as possible, being designed to "clear the path" for the right decisions by intentionally limiting and challenging biases, recurring to experts when faced with technical details, and so on (see Estlund 2008, chap. 8).

This, the fairness of its procedures, seems to me as a valid parameter for testing how well a democracy is performing in epistemic terms. What matters is that the decision-making institutions are designed to achieve the right decisions, not that they are right every time. Someone might contend that this parallel is not appropriate for a scaling reason, since juries must only make binary guilty/not guilty decisions, while democracies are normally faced with a wide variety of alternatives. Also, juries are constituted by a reduced number of citizens, while contemporary democracies usually enfranchise millions of them. Nevertheless, I think that these facts only make fairness and epistemic orientation a more important deal for a democracy, as I will discuss now.

Biases and misinformation grow considerably with more decision-making agents involved, more decisions to take, more possible outcomes, and more factors to weigh in. That fact alone makes the whole objective of "clearing the path" more desirable: if epistemic considerations are not introduced in the procedure, the results may end up being systematically skewed. Additionally, the greater number of people involved in making the decisions can also be thought as an advantage instead of a handicap. No one among democratic theorists thinks 
that contemporary democracies should be organized as Athenian assemblies; representative, deliberative, and participatory theorists alike envision complex arrangements that divide the work of democratic government among different institutions, with different purposes. If designed appropriately, the complexity of those institutions can substantially limit biases and foster "truth-tracking properties" (Landemore 2017) in the decision-making process. For example, the greater number of citizens that constitute those institutions can be used to introduce and foster diversity into the democratic procedure, which Landemore (2013) has defended (from both a normative and an empirical perspective) as more epistemically valuable than expertise.

\section{Relevant evidence and affected interests}

Let us assume that epistemic democracy theories are right, and democracy's truthtracking properties should be encouraged. A key dimension of these properties is the fair consideration of all relevant evidence. As part of their fair and epistemic-oriented process, juries attempt to fairly consider all relevant evidence for the decision they need to make. They must have some serious doubts about the origin or reliability of some piece of evidence in order to reject even the possibility of considering it. Moving this to the democratic domain, the main type of "evidence" (or epistemic input) that democracies need to consider fairly is constituted by the expressed preferences of democratic agents.

Nowadays it is a truism that only a slender percentage of democratic agents' voices should not be taken into fair consideration, i.e. the ones that clearly and deliberately attempt to promote hate speech, bring instability to democracy, etc. Denying or restricting the fair consideration of the expressed preferences of anybody else is deemed as a serious transgression to core democratic principles. Following this, I argue that democracy should also consider fairly another type of evidence or epistemic input, aside from democratic agents' voices: the interests of democratic patients.

Why are democratic patients entitled to the fair consideration of their interests? To argue for this, I refer to the intuitive force of the All-Affected Principle (Goodin 2007). This principle, embodied in core democratic values, proposes that everyone affected by a political decision should have a say on its forging ${ }^{4}$. Crucially, the heart of All-Affected Principle is political equality, expressed in "the central democratic doctrine of government by the governed" (Garner 2017, 466). 
Of course, democratic patients are unable to govern themselves directly, because they are, by definition, non-agents. However, this does not mean that the All-Affected Principle does not apply to them. If their interests can be somehow determined or approximated, they can be given an indirect voice through proxies (Garner 2017, 467-68). Why would some entity's voice be disregarded in the decision-making process, given that their interests are affected by democratic outcomes? To arbitrarily shut voices up clearly goes against the All-Affected Principle, and by extension, against core democratic values.

From this argument follows that democratic patients should have a place of their own in democratic theory: their interests should be fairly considered as evidence in the decisionmaking process. Nevertheless, it should be noted that this is not the same as saying that their interests should be necessarily satisfied ${ }^{5}$. They just need to be fairly considered: if some other considerations are stronger, then their interests would simply end up unsatisfied under a fair and truth-seeking democratic process. This is the same to what we expect of democracy when only considering agents: the ideal is to respect every voice and provide fair channels for their expression, not to attempt to fulfill every interest in stake.

That last remark speaks to the core of my argument. Throughout this paper I am not suggesting that we should primarily conceive democracy as a mechanism for fulfilling or maximizing interests, as would be defended by some extreme form of utilitarianism. Instead, I am claiming that we should consider the democratic decision-making process as a space in which entities are respected through the fair consideration of their interests. Moreover, those entities should not only be democratic agents, but also democratic patients, non-agents whose interests are affected by democratic outcomes.

To sum up, in this section I have presented the basis of my argument. The main idea is that democratic patients should have a place of their own in democratic theory. Democratic patients are entities that (a) are not capable of democratic agency, (b) have interests, and (c) have those interests affected by democratic decisions. Here I argued that we ought to fairly consider democratic patients' interests in the democratic process, because doing so aligns with the core democratic values represented by the All-Affected Principle. I claimed that democracy should not arbitrarily reject relevant evidence, which includes democratic patients' interests (as they are affected by the outcome of democratic decisions). It should be noted, as I explained above, that here I am talking about fair consideration of interests instead of satisfaction of interests. My focus is on respecting entities throughout the democratic process, not on merely using democratic institutions as a means to maximize certain entities' satisfaction of interests. 


\section{Defining democratic patients}

Let us remember the three defining characteristics of democratic patients: they (a) are not capable of democratic agency, (b) have interests, and (c) have their interests affected by democratic outcomes. What makes an entity (not) capable of democratic agency? How can we determine whether they have interests? How do we know what interests are affected by democratic outcomes? In what follows, I will briefly review competing theories that attempt to answer these questions. I do so to outline the complexity of arriving at a fixed set of democratic patients. At the end of this section, explore the case of future humans to show how we can assess whether a particular entity should be considered a democratic patient.

\section{(a) The limits of democratic agency}

Which entities are capable of democratic agency? I refer to this question as the one for (democratic) agency limits. In order to explore its possible answers, one needs to start by making a distinction between two close but essentially different aspects of agency, namely, between a certain arrange of actions that constitute democratic agency as such, and an entity's ability to perform those actions effectively.

To illustrate, let us think about women in the early democratic societies of the 19th century. As it is widely known, given the several restrictions both social and political institutions placed on them, those women were far from being de facto democratic agents. However, that is not the same as saying that they were not capable of democratic agency. As far as common knowledge suggests, voting, deliberating in the public sphere ${ }^{6}$, lobbying, participating on unions, street protesting, and other closely related actions are the standard expressions of democratic agency. Since it is clear to us that women can perform those actions (and that they were capable of doing so in the 19th century), we can meaningfully say that they are (and were) capable of democratic agency. From this example follows that, to assess whether an entity is capable of democratic agency, one needs to take into account the intersection of the two following aspects: what actions one believes to be constitutive of democratic agency and whether the entity examined is able to perform them.

Several political theorists have claimed that the pool of actions constitutive of democratic agency should not be as rigid as common knowledge suggests. In the following paragraphs I will review some proposed additions to that set of actions, paying special attention 
to the entities that might be capable of performing them (aside from adult humans who are not severely cognitively disabled).

Let us begin by exploring the idea of artistic performance as a distinct form of democratic agency (Mouffe 2007). It is not only claimed that art can be politically oriented which is rather obvious-, but also that the performance of art itself is a political statement valuable for democratic societies. Chantal Mouffe states it as follows: "There is an aesthetic dimension in the political and there is a political dimension in art. This is why I consider that it is not useful to make a distinction between political and non-political art" $(2007,4)$. If Mouffe is right, being capable of making art would lead to being capable of democratic agency. For instance, as Stacy Clifford (2012) mentions, artistic performance may serve as a form of embodied communication for people with profound disabilities. That might allow them to participate as distinct agents in a democratic setting, by the means of provoking new conversations and -potentially- making claims collaboratively (Clifford 2012).

A different proposal can be found in the work of Marc Jans (2004), who exhorts us to reconsider what we think about children's agency in democratic societies. He argues that we should consider children as democratic agents ${ }^{7}$, claiming that "their agency is a complex interaction in which children simultaneously are determined by their environment and help determine their environment"8 (Jans 2004, 39). Notice that Jans takes a different path from the one I am sketching here: he starts by discussing children qualities and then states that some of those qualities can be conceived as a form of democratic agency. The result is the same: a proposal about what actions should be labeled as democratic agency (interactions in which the entity determines and is determined by their environment) and entities that are capable of those actions (children) and, therefore, are capable of democratic agency.

More generally, the recent work of Sue Donaldson and Will Kymlicka (2017) seems to point at a similar direction". They challenge a strictly linguistic conception of the limits of agency, closely tied with "capacities for public reason or logos or Kantian autonomy or rational reflection and deliberation -complex language-mediated capacities..." (Donaldson and Kymlicka 2017, 169). They suggest, instead, that the group of democratic agents ought to be expanded by including all entities with "the capacity for norm responsiveness in intersubjective relationships -the ability to moderate behaviour in accord with internalized norms when relating to other selves" (Donaldson and Kymlicka 2017, 170). They believe that accepting that assessment significantly broadens the group of democratic agents, possibly including severely 
cognitively disabled humans, children, and some non-human animals (Donaldson and Kymlicka 2017).

In a different turn, Teena Gabrielson (2016) challenges the very notion of agency -in the context of environmental politics- as an individual quality, without saying that individuals are not agents. She sees agency "not as an attribute of the subject, but as widely distributed, temporally emergent, and collectively expressed" (Gabrielson 2016, 405). From there she can expand the limits of agency easily, by acknowledging that collective relations expand far beyond the mere human realm. She metaphorically refers to "a dance of agency, that includes the human, non-human nature, and artifice" (Gabrielson 2016, 405). She examines wildfire as a context for the emergence of agency (Gabrielson 2016, 408-9), connecting the lives and actions of humans (firefighters, public officials, locals, and so on) and non-human life forms that inhabit the forest in danger. All those entities might be thought as capable of agency, as long as they are vital parts of collectives from which agency emerges.

To sum up, the limits of democratic agency are set by the intersection of two closely related but different things: the pool of actions one considers to be constitutive of democratic agency, and the entities who are capable of performing them. Common knowledge and mainstream democratic theory suggest that voting, deliberating in the public sphere, lobbying, participating on unions, street protesting and other closely related actions express democratic agency. I have reviewed some proposed additions to said pool: making art, affecting and being affected by the environment, being capable of norm responsiveness in intersubjective relationships, and belonging to collectives in which lives and actions are intertwined. Attached to those proposals, new entities might be considered as capable of democratic agency: severely cognitively disabled humans, children, animals, and even non-animal life forms.

The positions one takes in respect to this discussion are crucial for the main argument of this paper -the case for democratic patients-, because defining characteristic (a) of democratic patients is that they are not capable of democratic agency. For instance, if one thinks that children should be considered democratic agents, as seems to follow from Jans' (2004) proposal, they could not be democratic patients, even if they met defining characteristics (b) and (c).

\section{(b) Possession of interests}

As I have stated before, in order to be a democratic patient an entity also needs to (b) possess interests. What attributes of an entity makes them a possessor of interests is indeed a 
question that raises considerable discussion. Nevertheless, at least the initial part of the debate, moving past a purely mentalist notion of what interests are, seems established in the current literature. Robert Goodin provides a good summary of the discussion:

One of the first moves in the modern analytics of interests is to draw a sharp distinction between
'interest' in the sense of 'what one takes an interest in' and in the sense of 'what one has an interest
in'. Eliding the two is a clear conceptual error. It empties the space between the notion of a 'want'
and an 'interest', thereby depriving the latter concept of any distinctive role or any independent
analytic leverage. .. Kicking away those mentalist props, we are left with a notion of interests as
much more akin to objective values. (1996, 836) (original emphasis)

Be that as it may, the debate is far from settled regarding what those 'objective values' are or might be. This is crucial, because different objective values would mean that different entities would be considered as possessors of interests.

Take non-human animals, for example. In one of the milestones of the animal liberation movement, Peter Singer (1974) argued $^{10}$ that the capacity to experience pleasure and pain is what constitutes interests. His argument is simple yet compelling: it is intuitive that any sentient entity has both an interest in experiencing pleasure and, accordingly, an interest in not experiencing pain.

We can easily derive this statement from our own lives, as seeking pleasure and avoiding pain is clearly in our interests. If that is the case for us, why would that basic link between experiences and interests be any different for $\operatorname{dog}^{11}$ ? Singer then concludes that every sentient entity has interests. From this, it follows that the universe of sentient entities goes far beyond the "usual suspects" that would be the only possessors of interests under the aforementioned mentalist conception. It can also include, as Singer notes, children, severely cognitively disabled humans, and most animals.

More recent theoretical developments have challenged Singer's perspective, attempting to expand its range of inclusion. For example, Gary Varner (1998) claims that not only sentient entities have interests, but also every other living organism, because biological needs and functions constitute interests. This is a position that has also been reaffirmed by Alfonso Donoso (2017) in the context of environmental politics. It is claimed that living organisms have an interest in following the non-mentalized path of fulfilling their biological needs and functions.

For instance, arguably the most basic biological function, staying alive, might be a good example here. Let us begin by separating death from any social and phenomenological experiences (therefore excluding desires, subjectivity, mind states, pain, suffering, and so on). 
Imagine a living entity ${ }^{12}$ at time $t$ and the same entity under two possible states at time $t+1$ : one in which they remain alive and another one in which they are dead. Can we say, from a perspective of interests, that those two possible states at time $t+1$ would be the same for the entity? To affirm that would be to deny any value in preserving the flow of life, in preserving its (non-mentalized) path-driven momentum. If one disagrees, as Varner (1998) and Donoso (2017) do, then that living entity is a possessor of interests: it has an interest in being alive, at the very least.

To summarize this subsection, I have reviewed the literature around defining characteristic (b) of any democratic patient, being a possessor of interests. I explored two theories that define which attributes an entity needs to have in order to possess interests. While Singer (1974) argues that the capacity for experiencing pleasure and pain makes an entity a possessor of interests -with corresponding interests on experiencing pleasure and avoiding pain-, Varner (1998) simply focuses on the act of living itself, from which an interest on fulfilling basic functions and needs can be derived. Although not within the scope of this article, stating what makes an entity a possessor of interests is necessary to define the group of democratic patients clearly. For example, if one agrees with Singer but not with Varner, nonanimal life forms could not be considered democratic patients (because they would not be possessors of interests), but all sentient animals might be if they meet the other two defining characteristics, (a) and (c).

\section{(c) Democratic outcomes and affected interests}

Defining attribute (c) of democratic patients requires the entity in question to have their interests affected by democratic outcomes. Even though the central tenet of this approach seems straightforward, it still requires further examination, as Robert Goodin (2007) holds. Would the entity need to be affected by democratic outcomes at all times? Would they need to be actually affected by democratic outcomes, or would it be sufficient for them to be affected potentially? The objective of this subsection is slightly different from the previous ones. It does not review different theories, instead following Goodin's (2007) discussion on what can be meaningfully said about having one's interested affected by democratic outcomes. I will begin by introducing the main possible variations of the All-Affected Principle, a task that is needed to assess (c) meaningfully when examining a particular entity.

Simply put, the All-Affected Principle states that, in a democracy, "all affected interests should have a say" (Goodin 2007, 50). Here I focus on Goodin's discussion about how 
to put this principle into practice, specifically about which interests would meaningfully count as affected by democratic outcomes. He begins by evaluating the most straightforward formulation of the principle while trying to apply it to reality, the All-Actually-Affected Principle. Goodin dismisses that formulation quickly, because of its logical impossibility: in order to know what interests are actually affected, the policy path needs to have already happened (Goodin 2007, 52-53).

Next, Goodin considers the All-Possibly-Affected Principle (2007, 53-55). Although not constrained by a logical impossibility, its implications are immense: the universe of entities possibly affected by democratic outcomes would virtually encompass all possible entities, of all possible universes, at all possible times. It is not only a matter of the "butterfly effect"-how fundamentally unpredictable policies might be-, but also of how non-chosen decisions might affect interests too. Even not choosing some policy affects all of those who might have been affected by its execution! In Goodin's words, this formulation of the All-Affected Principle would entail the defense of a "genuinely global, timeless democracy" $(2007,55)$.

It is reasonable to feel uncomfortable about the never-ending expansiveness of said formulation, that would entail an extreme precautionary principle: no matter how unlikely some consequence of a proposed policy might be, those affected by it would make the cut for serious interests' consideration. Consider Harsanyi's take on the precautionary principle, generally applied: "[i]f you took the maximin principle seriously you could not ever cross the street (after all, you might be hit by a car); you could never drive over a bridge (after all, it might collapse); you could never get married (after all, it might end in disaster); etc." (quoted in Goodin 2007, 60). While the All-Possibly-Affected Principle would not necessarily require us to abandon certain policies because of some unlikely yet possible consequence, it would indeed require us to take into account an almost endless stream of considerations. When deciding about building a hospital, we would need to think about every individual worker that might get injured in the construction site; when deciding about setting a new holiday, we would need to think about someone who might meet the love of their life during that workday, etc.

Noting this problem, Goodin suggests that we can replace the word "possibly" with "probably", arriving at the All-Probably-Affected principle" (Goodin 2007, 59-62). This new formulation of the All-Affected Principle would need to recur to probabilistic information about "whether the interest in question would actually be affected (by any of the possible decisions arising out of any of the possible agendas)" (Goodin 2007, 61). Although that sounds more reasonable than the previous formulation, it should still be noted that the body of considerations 
to make under the "all probably affected principle" would likely still be quite extensive, because of the wide range of decisions contemporary democracies make. While this formulation would not make us consider every unlikely interest affected by a particular policy decision, it is nevertheless plausible to think that in the process of adding up all the policy decisions that a contemporary democracy needs to make, a wide range of different probably affected interests would arise.

To sum up, in this subsection I have followed Goodin's (2007) discussion about the possible formulations of the All-Affected Principle, which states that everyone affected by a decision should have a said on its forging. While the All-Actually-Affected Principle arrives at a logical impossibility -it is impossible to know what interests are actually affected before the democratic decision takes place-, the All-Possibly-Affected Principle seems too demanding for actual democracies. The most promising formulation is the All-Probably-Affected Principle, which would recur to probabilistic information for determining which interests might be plausibly affected by democratic outcomes. Following this, an entity would need to be probably affected by democratic outcomes in order to satisfy defining characteristic (c) of democratic patients. However, as I have stated above, this statement is quite extensive. In all likelihood, almost every entity with interests has them probably affected by democratic outcomes when the full range of policy paths is considered. That means that, prima facie, every entity that meets defining characteristics (a) and (b) would be a democratic patient, because (c) would be almost automatically granted.

\section{Future humans as democratic patients}

While the considerations above should provide a good starting point for judging whether most of the initial candidates ${ }^{13}$ would be democratic patients, I have not discussed yet the case of non-existent future humans. Let me focus on them now ${ }^{14}$. It should be noted that my objective here is not to comprehensively defend future humans as democratic patients. Instead, the idea is to illustrate how to evaluate whether an entity should be considered one.

Recall the three defining characteristics for calling an entity a democratic patient: they need to (a) be incapable of democratic agency, (b) have interests, and (c) have those interests affected by democratic outcomes. If future humans lived right now, solving these assessments would probably not be controversial, since they would be -we can safely assume- quite similar to us. Crucially, however, future humans do not exist yet. Can we say that they are not 
democratic agents, that they have interests, and that democracy's outcomes affect them? That is, can we say that they are democratic patients in the present?

First, it is not hard to argue that they meet defining characteristic (a). While it is probably safe to assume that future humans will eventually be agents, they are currently incapable of democratic agency. None of the cutting-edge theories of agency discussed before (§2a) seems to amend the fact that agency needs to be exercised now, to have some repercussions in the current democratic scenario.

Next, the question of (b), interests' possession, arises: do future humans possess interests now? The answer to these questions is less straightforward. Consider Joel Feinberg's classic misanthrope example:

A wicked misanthrope desires to blow up a schoolhouse in order to kill or mutilate the pupils. He conceals a bomb in a closet in the kindergarten room and sets a timing device to go off in six years. It goes off on schedule, killing or mutilating dozens of five-year-old children. $(1986,154)$

The most interesting part of this example is that when the misanthrope plants the bomb, none of the children that will be damaged has come to existence. However, it seems to be in line with any meaningful definition of interests to say that the children of the example have an interest on the bomb not to be planted, or on it to be defused (even before they are born). For practical considerations, then, the temporal distinction between having interests now and potentially having them in the future is usually disregarded. Robert Goodin, for example, simply says that "future generations clearly have interests, or anyway they will have" $(2003,211)$. Some other contemporary authors discussing similar topics also appear to assume this, without being as explicit as Goodin (see Meyer 2016; Kates 2015; Davidson 2008).

Now let us turn to (c), whether future people have their interests affected by contemporary democratic decisions. Of course, the relationship between the misanthrope's decision to plant a bomb and the children's affected interests is way clearer than the general relationship between our democratic decisions and the interests of future people. However, as I have noted earlier, one can use the All-Probably-Affected Principle in order to state (c) meaningfully, as we have good reasons to think that our current political decisions will affect them. The fact that a vast range of the political decisions taken by previous generations affect us deeply -think as big as the French Revolution and as small as the street lighting in your neighborhood- is probably a good indicator of how it is going to work for future generations. If that inductive evidence is not enough, one can turn to scientific prediction, for instance, about 
how climate change is most likely going to devastate the lives of multiple future humans (see Stocker et al. 2014).

\section{Final remarks: an institutional challenge}

Translating the case for democratic patients into real-world institutions is not a straightforward task. Although I do not intend to provide a comprehensive plan here, I will attempt to outline some initial remarks. First, consider the current state of affairs, which is only to care about democratic patients' interests when democratic agents are willing to advocate for them. In the context of animal rights, Garner describes this position as "strong anthropocentrism":

... which holds that only human preferences regarding animals ought to be promoted. That is, the interests of animals ought not to be represented independently of human interests. ... That is, the interests of animals will be protected in a strong anthropocentric account of democracy only if enough humans want this to happen. (Garner 2017, 464)

However, this proves insufficient: democratic agents are systematically biased towards themselves and, more interestingly, might be towards the democratic patients they feel closer to (for example, see Kasperbauer 2017 for a psychological review of how humans perceive nonhuman animals distortedly). This casts doubt upon the idea that they can consider democratic patients' interests fairly. For instance, imagine that one's positions about the defining characteristics of democratic patients - (a), (b), and (c) - entail that young children are democratic patients ${ }^{15}$. Clearly democratic agents do not fairly consider the interests of all young children as of now, because they are (understandably) biased towards their own and the ones they are closer to -instead of, for example, orphaned children.

Now let us consider some alternatives to the current state of affairs that might help democracies to fairly consider the interests of democratic patients. A proposal that attempts to deal with this issue is the pursue of "deliberation within" (Goodin 2003). Simply put, the idea is that democratic agents should internalize the interests of (what I call) democratic patients and act accordingly in the political world. It may be thought as a new formulation of the democratic motto "one person, one vote": once the "deliberation within" has taken place, each vote (and individual position in the public debate, actually) does not only encompass the interests of the person that casts it, but also some other interests that are exogenous to them and, in the framework I am proposing, can be traced back to democratic patients.

However, I remain skeptical about the potential of that enhancement to be significant enough to qualify "deliberation within" as a fair way to consider democratic patients' interests. 
Even though empathy and internal changes of perspective are probably beneficial for democratic patients in general, what actually assures them fairness in political consideration lies in the structure of decision-making procedures. At least that is what we think about the historical struggle of those who were once mistakenly thought to be incapable of democratic agency. For instance, although changing men's mentalities towards women is arguably a good thing for feminist advocates, the real-world gains can only be assured by inclusive decisionmaking procedures that imbue them in durable institutions, like women's suffrage or gender quotas.

The challenge, then, is to design an institutional arrangement able to restructure the democratic decision-making procedures in a way that permits the fair consideration of democratic patients' interests. Multiple institutional proposals have been suggested to address closely related issues: proxy electorate/representatives (Dobson 1998; Ekeli 2005), submajority rules (Ekeli 2009), constitutional provisions (Gosseries 2008, 2014), ecological councils (Stein 1998; Donoso 2017), etc. Although I do not plan on extensively reviewing those proposed institutions, I will say that any mechanism attempting to address the challenge proposed by this article would have to carefully consider two points.

First, it should demonstrate how its institutional arrangements point towards achieving the fair consideration of democratic patients' interests. Like a jury, it should be designed to solve complex dilemmas and seek the truth through its procedures. While I do not plan on outlining this comprehensively, I think that any institutional proposal attempting to meet this challenge should at least provide mechanisms for doing the following: (i) define and/or be able to redefine the group of democratic patients in the light of new evidence, (ii) identify the interests of democratic patients, (iii) identify specific public policies that align with those interests, and (iv) be able to influence democratic outcomes in a way that is both proactive and reactive, that is, to be able to suggest new policy and react to existing or proposed policy ${ }^{16}$.

Those objectives should be pursued in a way that is epistemically-oriented, which leads to my second remark. Any democratic institution attempting to fairly consider the interests of democratic patients should, crucially, also respect democratic agents. The fact that new evidence is on the table should not mean that we can lazily disregard the previous, established sources. This point refers to the widely discussed tension between democratic participation and expertise (see Christiano 2012; Holst and Molander 2014). Expertise would be needed in order to identify the interests of the voiceless and to be able to articulate them in a meaningful way. However, expertise needs to be treated with care to avoid the temptation of epistocracy, the 
mere government of the experts (Estlund 2008), which goes against the respect to democratic agents ${ }^{17}$ expressed in core democratic principles. Any institution attempting to fairly consider the interests of democratic patients needs to improve democracy as a whole, not diminishing it on other flanks. 


\section{Notes:}

${ }^{1}$ Pontificia Universidad Católica de Chile, Santiago, Chile. E-mail: arcruz@uc.cl.

The research for this paper was generously supported by a FONDECYT Dissertation Grant (FONDECYT Iniciación \#11160170). I would also like to acknowledge the helpful input I have received from Dr Alfonso Donoso, Antoine Verret-Hamelin, Pedro Riquelme, Mauricio Oportus, Manuel Díaz, Danissa Contreras, and the participants of the 2017 International Meeting on Intergenerational Justice and Climate Change (Córdoba, Argentina). All errors are exclusively my own.

${ }^{2}$ I am going to assume an individual approach to environmental issues through this article.

${ }^{3}$ Although sortition was practiced in Athenian democracy and is even advocated by some theorists as a good democratic procedure for contemporary democracies (see Guerrero 2014), it should be noted that it is a procedure applied to only one of the many decisions that democracies make: the election of public officials. To my knowledge, no one has ever argued that democracies should flip a coin when deciding among competing laws (and attached policies) of abortion, immigration, taxes, etc.

${ }^{4}$ For a defense against the All-Affected Principle most common objections, see Garner 2017, 466-67.

${ }^{5}$ My thanks to Pedro Riquelme for pointing out this very important distinction to me.

${ }^{6}$ Deliberating in the public space may be broader than usually thought. Some authors argue that rational discourse is just a part of it, and that deliberation also includes the paralinguistic and nonverbal properties of communication (see Young 2000, chap. 2). Besides, deliberation does not necessarily need to happen in institutional contexts: for instance, Mansbridge (1999) argues that everyday talk is a key aspect of deliberation. My thanks to Antoine VerretHamelin for reminding me of this.

${ }^{7}$ The author is specifically talking about children as citizens. However, one of the constitutive dimensions that he identifies in citizenship is participation (Jans 2004, 38) and his scope seems to be restricted to democracies (2004, $30)$.

${ }^{8}$ If taken to its full extent, this is a very broad definition of agency, that could even include non-living entities. Think of a river, for example. It definitely determines the environment around it, creating entire ecosystems in which, for instance, plants and animals live. And it is also determined by the environment: topological features shape it, beaver dams can alter its course, etc. Thanks to Antoine Verret-Hamelin for drawing my attention to this point.

${ }^{9}$ Like Jans (2004), the authors make their points from the venue of citizenship theory. Nevertheless, their focus on democracy and agency is evident, even being mentioned in the title of the article, "Rethinking membership and participation in an inclusive democracy" (Donaldson and Kymlicka 2017) (emphasis added).

10 Note that, although Singer derives utilitarian conclusions from this position about which entities possess interests, that does not mean that the position is utilitarian by itself. The main framework mainly speaks to common sense morality; see Horta (2011). Thanks to Pedro Riquelme for pointing this out to me.

${ }^{11}$ We would need to assume that dogs find joy in some activities and suffer from others. That does not sound implausible at all to anyone that has actually spent some time with a dog!

12 That living entity might be either yourself or a tree: the aforementioned exclusion about social and phenomenological experiences should make the distinction irrelevant in this case.

${ }^{13}$ Young children, severely cognitively disabled humans, sentient animals, and non-sentient life forms.

14 Variations of the following discussion can be formulated about future individuals of the other candidates announced earlier, for example, future non-human animals.

${ }^{15}$ Note that this would require the rejection of Jans' (2004) proposal regarding the democratic agency of children, because of defining characteristic (a) of democratic patients. 
${ }^{16}$ A reactive institution, for example, might act as a veto player for legislative motions concerning democratic patients

${ }^{17}$ Avoiding epistocracy is a difficult challenge, that probably needs us to think deeply about the interactions between science and democracy (for example, see Brown 2015, 2016). 


\section{References}

Brown, Mark B. 2015. "Politicizing Science: Conceptions of Politics in Science and Technology Studies." Social Studies of Science $45 \quad$ (1): 3-30. https://doi.org/10.1177/0306312714556694.

. 2016. "Environmental Science and Politics." In The Oxford Handbook of Environmental Political Theory, edited by Teena Gabrielson, Cheryl Hall, John M. Meyer, and David Schlosberg, 491-504. Oxford: Oxford University Press.

Christiano, Thomas. 2012. "Rational Deliberation among Experts and Citizens." In Deliberative Systems, edited by John Parkinson and Jane Mansbridge. Cambridge: Cambridge University Press.

Clifford, Stacy. 2012. "Making Disability Public in Deliberative Democracy." Contemporary Political Theory 11 (2): 211-28. https://doi.org/10.1057/cpt.2011.11.

Davidson, Marc. 2008. "Wrongful Harm to Future Generations: The Case of Climate Change." Environmental Values 17 (4): 471-88.

Dobson, Andrew. 1998. "Representative Democracy and the Environment." In Democracy and the Environment, edited by William E. Lafferty and James Meadowcroft, 124-39. Cheltenham: Edward Elgar.

Donaldson, Sue, and Will Kymlicka. 2017. "Rethinking Membership and Participation in an Inclusive Democracy: Cognitive Disability, Children, Animals." In Disability and Political Theory, edited by Barbara Arneil and Nancy Hirschmann, 168-97. Cambridge: Cambridge University Press.

Donoso, Alfonso. 2017. "Representing Non-Human Interests." Environmental Values 26 (5): 607-28. https://doi.org/10.3197/096327117X15002190708137.

Ekeli, Kristian. 2005. "Giving a Voice to Posterity - Deliberative Democracy and Representation of Future People." Journal of Agricultural and Environmental Ethics 18 (5): 429-50. https://doi.org/10.1007/s10806-005-7048-z.

—. 2009. "Constitutional Experiments: Representing Future Generations Through Submajority Rules." Journal of Political Philosophy 17 (4): 440-61. https://doi.org/10.1111/j.1467-9760.2008.00328.x.

Ellis, Elisabeth. 2016. "Democracy as Constraint and Possibility for Environmental Action." In The Oxford Handbook of Environmental Political Theory, edited by Teena Gabrielson, Cheryl Hall, John M. Meyer, and David Schlosberg, 505-19. Oxford: Oxford University Press.

Estlund, David M. 2008. Democratic Authority: A Philosophical Framework. Princeton University Press. 
Feinberg, Joel. 1986. "Wrongful Life and the Counterfactual Element in Harming." Social Philosophy and Policy 4 (1): 145-78. https://doi.org/10.1017/S0265052500000467.

Gabrielson, Teena. 2016. "Bodies, Environments and Agency." In The Oxford Handbook of Environmental Political Theory, edited by Teena Gabrielson, Cheryl Hall, John M. Meyer, and David Schlosberg, 399-412. Oxford: Oxford University Press.

Garner, Robert. 2017. "Animals and Democratic Theory: Beyond an Anthropocentric Account." Contemporary Political Theory 16 (4): 459-477. https://doi.org/10.1057/s41296-016-0072-0.

Goodin, Robert E. 1996. "Enfranchising the Earth, and Its Alternatives." Political Studies 44 (5): 835-49.

_. 2003. "Representing Mute Interests." In Reflective Democracy. Oxford: Oxford University Press.

- 2007. "Enfranchising All Affected Interests, and Its Alternatives." Philosophy \& Public Affairs 35 (1): 40-68. https://doi.org/10.1111/j.1088-4963.2007.00098.x.

Gosseries, Axel. 2008. "Constitutions and Future Generations.” The Good Society 17 (2): 3237.

2014. "The Intergenerational Case for Constitutional Rigidity." Ratio Juris 27 (4): 528-39. https://doi.org/10.1111/raju.12060.

Guerrero, Alexander A. 2014. “Against Elections: The Lottocratic Alternative." Philosophy \& Public Affairs 42 (2): 135-78. https://doi.org/10.1111/papa.12029.

Holst, Cathrine, and Anders Molander. 2014. "Epistemic Democracy and the Accountability of Experts." In Expertise and Democracy, edited by Cathrine Holst, 13-35. ARENA Report Series, 1/14. Oslo: ARENA Centre for European Studies.

Horta, Oscar. 2011. "La Argumentación de Singer En Liberación Animal: Concepciones Normativas, Interés En Vivir y Agregacionismo.” Diánoia 56 (67): 65-85.

Jans, Marc. 2004. "Children as Citizens: Towards a Contemporary Notion of Child Participation.” Childhood 11 (1): 27-44. https://doi.org/10.1177/0907568204040182.

Kasperbauer, T. J. 2017. "Mentalizing Animals: Implications for Moral Psychology and Animal Ethics." Philosophical Studies 174 (2): 465-84. https://doi.org/10.1007/s11098016-0692-5.

Kates, Michael. 2015. "Justice, Democracy, and Future Generations." Critical Review of International Social and Political Philosophy 18 (5): 508-28. https://doi.org/10.1080/13698230.2013.861655.

Landemore, Hélène. 2013. Democratic Reason: Politics, Collective Intelligence, and the Rule of the Many. Princeton, NY: Princeton University Press. 
2017. "Beyond the Fact of Disagreement? The Epistemic Turn in Deliberative Democracy." Social Epistemology $31 \quad$ (3): https://doi.org/10.1080/02691728.2017.1317868.

Mansbridge, Jane. 1999. "Everyday Talk in the Deliberative System." In Deliberative Politics: Essays on Democracy and Disagreement, edited by Stephen Macedo, 211-39. Oxford: Oxford University Press.

Meyer, Lukas. 2016. "Intergenerational Justice.” In The Stanford Encyclopedia of Philosophy, edited by Edward N. Zalta, Summer 2016. Metaphysics Research Lab, Stanford University. https://plato.stanford.edu/archives/sum2016/entries/justice-intergenerational/.

Mouffe, Chantal. 2007. "Artistic Activism and Agonistic Spaces." Art \& Research 1 (2). http://www.artandresearch.org.uk/v1n2/mouffe.html.

Saunders, Ben. 2012. "Defining the Demos." Politics, Philosophy \& Economics 11 (3): 280301. https://doi.org/10.1177/1470594X11416782.

Singer, Peter. 1974. “All Animals Are Equal.” Philosophical Exchange 5 (1): 103-16.

Stein, Tine. 1998. "Does the Constitutional and Democratic System Work? The Ecological Crisis as a Challenge to the Political Order of Constitutional Democracy." Constellations: An International Journal of Critical \& Democratic Theory 4 (3): 420-49.

Stocker, Thomas F., Dahe Qin, Gian-Kasper Plattner, Melinda M. B. Tignor, Simon K. Allen, Judith Boschung, Alexander Nauels, Yu Xia, Vincent Bex, and Pauline M. Midgley, eds. 2014. Climate Change 2013: The Physical Science Basis. Contribution of Working Group I to the Fifth Assessment Report of IPCC the Intergovernmental Panel on Climate Change. Cambridge: Cambridge University Press.

Varner, Gary. 1998. In Nature’s Interests? Oxford: Oxford University Press.

Young, Iris Marion. 2000. Inclusion and Democracy. Oxford: Oxford University Press. 